\title{
“EL MISMO INDIO ESTÁ HABLANDO!’: SOBRE EL INTERCAMBIO EPISTOLAR ENTRE HUGO BLANCO Y JOSÉ MARÍA ARGUEDAS
}

\author{
“THE SAME INDIGENOUS IS TALKING!”: ON THE EPISTOLAR EXCHANGE \\ BETWEEN HUGO BLANCO AND JOSÉ MARÍA ARGUEDAS
}

\author{
Luis Andrade Ciudad ${ }^{*}$ Giovanna Pollarolo*
}

\begin{abstract}
A fines de los años sesenta se produjo un breve pero importante intercambio epistolar entre quienes tal vez fueron los más significativos actores de los escenarios literario y político-social en el Perú de ese entonces: el escritor José María Arguedas y el dirigente campesino Hugo Blanco (“Correspondencia...," 1969). Hijos de familias mistis o "decentes" del sur andino, devenidos en voceros de los sectores indígenas del Ande, intercambiaron tres cartas, escritas en quechua, de una inusitada ternura e intensidad, incluso tomando en cuenta el copioso e intenso corpus epistolar del escritor (Forgues, ed. 1993; Murra y López-Baralt, eds. 1996; Pinilla, ed. 2007; Pinilla, ed. 2011a, 2011b; Westphalen, comp. 2011). Casi cincuenta años después, y tras varias entrevistas realizadas a un ya octogenario Hugo Blanco, nos preguntamos por el significado subjetivo de estos textos, redactados en un contexto marcado por cambios radicales en Perú, en el pensamiento político de Arguedas y en su vida personal. Era un momento muy distinto en términos vitales para ambos actores: mientras que a Hugo Blanco se le había ratificado la sentencia de prisión por veinticinco años hacía ya tres años, librándolo de la pena capital, Arguedas había decidido quitarse la vida. Intentaremos observar cómo se reflejan en las cartas ambos momentos vitales e identificar los factores que marcaron el encuentro, entre estos resaltamos la construcción de la autenticidad indígena (Bucholtz 2003; Bucholtz y Hall 2005) por el uso del quechua y mediante la exaltación de la imagen

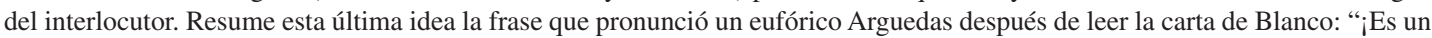
indio! ¡Puro indio!” (Vidales 1975), a la que hizo eco la exclamación del dirigente campesino en su segunda carta, cuando recordó lo que había sentido después de leer Los ríos profundos: “Ya está, carajo, ahora el mismo indio está hablando!”.
\end{abstract}

Palabras claves: José María Arguedas, Hugo Blanco, identidad indígena, literatura y política, quechua.

At the end of the 1960s, a brief but meaningful epistolary exchange developed between two of the most significant actors of the literary and political arenas in Peru: the writer José María Arguedas and the political peasant leader Hugo Blanco ("Correspondencia...", 1969). Born into misti or "white" families, and afterwards turned into spokespeople of the indigenous Andean groups, Arguedas and Blanco exchanged three letters, written in Quechua, marked by a noteworthy tenderness and intensity, even taking into account the abundant and impassioned epistolary corpus of the writer (Forgues, ed. 1993; Murra and López-Baralt, eds. 1996; Pinilla, ed. 2007; Pinilla, ed. 2011a, 2011b; Westphalen, comp. 2011). Almost fifty years later, and after a series of interviews with an octogenarian Hugo Blanco, we address in this paper the subjective meaning of those texts, written in a context signaled by extreme changes in Peru, in Arguedas' political thought as well as in his private life. It was a period marked by distinctive life-and-death experiences for both actors. While a prison sentence for twenty-five years had relieved Blanco of the possibility of death penalty three years before the exchange, Arguedas decided to commit suicide few days after the communication. We will explore how the letters reflect both biographical moments and will characterize the main features of this brief epistolary relationship, among which we stress the construction of indigenous authenticity (Bucholtz 2003) by means of using Quechua and praising the interlocutor's face. The latter trend is clearly summarized by a statement pronounced by a euphoric Arguedas after reading Blanco's letter: “iHe is an Indian! iA pure Indian!” (Vidales 1975). This exclamation was echoed by the peasant leader, when he recalled, in his second letter, what he had thought after reading Los ríos profundos: “'There it is, carajo, the real Indian is speaking now!”.

Keywords: José María Arguedas, Hugo Blanco, indigenous identity, literature and politics, Quechua.

\section{Introducción}

"¡Ya está, carajo, ahora el mismo indio está hablando!". Esto fue lo que pensó el dirigente campesino Hugo Blanco después de leer la novela Los ríos profundos, de José María Arguedas, publicada en 1958 (“Correspondencia...”, 1969: 13-14). “¡Es un indio! ¡Puro indio!”, exclamó Arguedas, a su turno, cuando recibió la primera carta de Blanco, según el recuento del activista político colombiano Carlos Vidales (Vidales 1975), muy cercano en ese entonces a la pareja conformada por el escritor y Sybila Arredondo, quien décadas después, en 1990, sería condenada a prisión acusada de pertenecer

* Pontificia Universidad Católica del Perú. Departamento de Humanidades. Correos electrónicos: 1fandrad@pucp.edu.pe; pollarologiovanna@gmail.com 
a Socorro Popular, un organismo de apoyo del grupo terrorista Sendero Luminoso. Ambos, dirigente y escritor, nacidos en el seno de familias mistis o "decentes" del sur andino, habían dado un giro que cambió radicalmente sus trayectorias al identificarse con las luchas y las vidas de los sectores indígenas, y no escatimaron expresiones de entusiasmo al encontrar en sus respectivos interlocutores la confirmación de dicha indigenidad en este importante intercambio epistolar de fines de los años sesenta, muy poco antes del suicidio de Arguedas ${ }^{1}$.

En este artículo propondremos que este conjunto de textos -tres cartas escritas en quechua y luego traducidas al castellano por ambos personajes- exprese un momento importante de la historia política peruana reciente. Argumentaremos que este corpus deja vislumbrar, en primer lugar, aspectos claves del momento vital que Blanco y Arguedas atravesaban $\mathrm{y}$, en segundo término, algunas estrategias básicas para la construcción de su identidad étnica, en particular, el uso del quechua. La autenticidad indígena (Bucholtz 2003) descansa en buena parte, para estos actores, en el uso del idioma originario, así como en la exaltación de la imagen del interlocutor como un "indio verdadero". De este modo, queremos ensayar una lectura distinta de los apuntes básicamente políticos que se han hecho de estos textos, tanto desde la crítica literaria (Forgues 1996; Núñez 2016; Vargas Llosa 1995) como desde la teoría poscolonial (Pucci y Wainzieger Friedheim 2013).

Hugo Blanco estaba preso en la cárcel de El Frontón, una isla ubicada frente al puerto del Callao, cerca de Lima, desde 1966. Ya en 1966 el tribunal militar supremo que lo había juzgado por segunda vez le había ratificado la sentencia de prisión por veinticinco años, con esto se lo había librado de la perspectiva de la pena capital, gracias a una intensa campaña internacional en la que participaron instituciones como Amnistía Internacional e intelectuales como Jean-Paul Sartre y Simone de Beauvoir. En el momento del intercambio, José María Arguedas estaba, por su parte, terminando de tomar la decisión de quitarse la vida, decisión que concretaría el 28 de noviembre de 1969 en las instalaciones de la Universidad Nacional Agraria, cuatro días después de que Blanco le enviara su segunda carta. De este modo, la muerte y la vida signaban de distintas maneras las trayectorias de ambos personajes durante el intercambio epistolar.
Las cartas muestran una inusitada ternura e intensidad, incluso tomando en cuenta la copiosa producción epistolar del escritor en su conjunto (Forgues, ed. 1993; Murra y López-Baralt, eds. 1996; Pinilla, ed. 2007; Pinilla, ed. 2011a, 2011b; Westphalen, comp. 2011). Casi cincuenta años después de su escritura, y tras varias entrevistas realizadas a un ya octogenario Hugo Blanco, en este texto nos preguntamos por el significado subjetivo de estas cartas, en un contexto marcado por cambios radicales en Perú y en un momento vital tan cargado para ambos actores, tal vez los más significativos personajes de los escenarios literario y político-social en el Perú de ese entonces.

Las entrevistas con Blanco se realizaron entre setiembre del 2016 y enero del 2018². En el caso de Arguedas consideramos, asimismo, la radicalización de su pensamiento político, así como la crisis personal que padeció y que lo desbordó hasta terminar con su vida pocos días después del encuentro epistolar. Luego de exponer el contexto social en el que se produjo esta serie de comunicaciones, nos aproximaremos al momento vital que ambos actores atravesaban, para finalmente abordar los aspectos vinculados a la construcción recíproca de la identidad indígena.

\section{"Piedra y paloma": el contexto nacional y el momento vital}

En noviembre de 1969, cuando las cartas se escribieron, el militar populista y nacionalista Juan Velasco Alvarado ya se encontraba desde hacía un año en el poder, después de haber dado un golpe de Estado al primer gobierno de Fernando Belaúnde Terry. Sin embargo, durante todo ese año del nuevo gobierno, Hugo Blanco, apresado en 1963 en el Cusco después de las tomas de tierras de La Convención, no había sido liberado todavía. Recién en diciembre de 1970 sería indultado y meses después, en setiembre de 1971, deportado a México (Tauro del Pino 2001), para después pasar a Argentina, Chile y Suecia. El 24 de junio de 1969, Día del Campesino, Velasco decretó una radical reforma agraria, con el objetivo de transformar la estructura de propiedad de la tierra. De este modo, puso punto final al viejo régimen latifundista, basado en el sistema de haciendas, cambiándolo por un modelo de redistribución de la propiedad rural supuestamente equitativo, aunque luego se verían las limitaciones de este intento (Harding 
1975; Thorp 1995; Thorp y Bertram [1985] 2013, cap. 15). El discurso de promulgación de esta reforma concluyó así: "Al hombre de la tierra ahora le podemos decir en la voz inmortal y libertaria de Túpac Amaru: ‘'Campesino, el patrón ya no comerá más de tu pobreza!"”.

Este anuncio grandilocuente, amparado en la figura del líder de la mayor rebelión indígena que se produjo en la América hispana durante el siglo XVIII, tenía por lo menos un antecedente que Velasco no estaba reconociendo: las rebeliones campesinas de La Convención y Lares, en la ceja de selva del departamento del Cuzco, donde entre 1958 y 1964 se había producido, según el historiador Eduardo Fioravanti, "una de las revueltas campesinas contemporáneas más radicales de América Latina" (Fioravanti 1974: 3) ${ }^{3}$. Dichas revueltas habían logrado, según este académico, llevar adelante una reforma agraria favorable a los intereses del estrato superior del campesinado, es decir, los arrendires o "colonos", quienes, en el espacio de la hacienda tradicional, recibían del hacendado o gamonal una parcela que cultivaban en usufructo a cambio de mano de obra. Ciertas modificaciones favorables a la producción de café, cultivo que se había introducido hacía pocos años en la ceja de selva cuzqueña, habían llevado a un replanteamiento de las condiciones de trabajo latifundista en una estructura alambicada, conformada no solo por el hacendado, sus capataces y el arrendire, sino también por los "allegados", "suballegados" y obreros agrícolas temporales que el arrendire debía subcontratar para cumplir con la cuota de mano de obra a la que estaba obligado. A ello se sumaba la aparición reciente del rescatista o comerciante, quien, atraído por la buena producción del café y los precios en alza, estableció alianzas directas con los campesinos cuzqueños en desmedro de los ingresos del hacendado (Handelman 1975: 72). En este marco se formaron, ilegalmente, los sindicatos campesinos, en los que Hugo Blanco asumió un papel protagónico después de convertirse en "allegado" de un arrendire de la hacienda de Chaupimayo (La Convención), Óscar Quiñones, a quien había conocido en la cárcel del Cuzco junto con otros dirigentes de la misma hacienda, Andrés Gonzales y Constantino Carrillo, que también se encontraban presos. "Así fue que me acampesiné", recuerda el dirigente (entrevista, 08/01/2018), quien presenta su propia visión del proceso en Blanco Galdós (2017: 57-91).
Fioravanti (1974: 204-205) narra la paulatina figuración que cobró Blanco con sus planteamientos revolucionarios derivados del trotskismo. Estos fueron recogidos con entusiasmo por los sindicatos campesinos de las haciendas de Huadquiña, Chaupimayo y Santa Rosa (en la provincia de La Convención) y en el valle de Lares (en la vecina provincia de Calca), frente a las posturas en competencia, más moderadas y legalistas, de la Federación de Trabajadores del Cusco, ligada al Partido Comunista (facción "estalinista", en las categorías de Blanco), posturas estas que fueron adoptadas en otros distritos convencianos, como Echarate y Maranura. Cuando se desataron las acciones, fue necesario para los indígenas levantados organizar "milicias campesinas" que "tenían como misión la defensa de las tierras conquistadas" (Fioravanti 1974: 203, cf. también Handelman 1975: 74). Al narrar los enfrentamientos con las fuerzas del orden que sobrevinieron a las tomas de haciendas y a la expulsión de los gamonales, los campesinos atribuyeron dimensiones casi míticas al dirigente trotskista. Fioravanti, quien tomó testimonios entre los campesinos del Cusco a inicios de los años setenta, apunta:

Los campesinos de La Convención relatan cómo Blanco siempre escapaba de la policía transformado en perro, en puma, en gato. Cuentan los campesinos que una vez llevaban a Blanco detenido en un Jeep, en un momento del viaje se detuvo y los policías descendieron para contemplar una res que se había despeñado por un barranco, cuando regresaron al coche para continuar la marcha oyeron un ladrido y vieron a un perro que salía por la puerta desapareciendo entre los matorrales. En el interior Blanco ya no estaba (Fioravanti 1974: 194).

También se le asignaban a Blanco dotes de ubicuidad:

De la misma manera Blanco aparecía en todas las provincias organizando sindicatos, se le veía al tiempo en Canchis, en Urubamba, en Espinar, castigando los atropellos de los hacendados y devolviendo las tierras a los campesinos. Muchos de estos piensan que nunca fue detenido y que anda organizando sindicatos en otras regiones del país (Fioravanti 1974: 194). 
Sin embargo, Blanco fue apresado en una emboscada en el Cuzco, en 1963, y juzgado en 1966 en Tacna, por un tribunal conformado sobre todo por miembros de la Guardia Civil, que lo sentenció a veinticinco años de cárcel por primera vez. El testimonio del propio Blanco, cincuenta años después, pone mucho énfasis en la astucia y energía que él mismo desplegó en ese episodio, así como en la solidaridad masiva que logró conquistar entre el pueblo tacneño e incluso entre los propios soldados y policías presentes en la audiencia, secretamente identificados con su causa. El momento culminante fue cuando al ser retirado de la sala judicial para ser trasladado a Lima, donde un tribunal militar supremo ratificaría la sentencia, el dirigente gritó "¡Tierra o muerte!", las tres palabras que habían simbolizado las acciones de los sindicatos campesinos cuzqueños. Y retumbó en la sala el grito de respuesta: “¡Venceremos!”.

La amplia cobertura de prensa que recibieron las acciones de Blanco y el campesinado convenciano, así como la posibilidad, presente en ambos juicios, de que se lo condenara a la pena de muerte, despertó una cadena de solidaridad internacional que llegó hasta instituciones de defensa de los derechos humanos y a intelectuales de la talla de Jean-Paul Sartre y Simone de Beauvoir. De hecho, el fiscal del tribunal militar que lo juzgó en Lima pidió la pena capital (Blanco 2017: 72). A pesar de que había sido detenido por la muerte de tres policías (en realidad, mató a uno en defensa propia, según el relato del propio dirigente), la sección sueca de Amnistía Internacional (AI) declaró a Blanco "preso del año". Como esta organización no apoya a personas que ejercen la violencia, se deduce que AI aceptó el carácter defensivo de este asesinato. La presión internacional se hizo cada vez más fuerte $\mathrm{y}$, en consecuencia, el tribunal ratificó la condena de veinticinco años en 1966. Años después, el gobierno de Velasco amnistiaría a Blanco, junto con otros dos presos políticos, y lo deportaría a México. Dos años antes de ser liberado, el dirigente conoció a Sybila Arredondo, quien ya era pareja de Arguedas, en el patio de la cárcel de El Frontón, donde ella iba a visitar a presos políticos del Movimiento de Izquierda Revolucionaria. La ahora viuda de Arguedas le entregó un ejemplar de Todas las sangres y en ese momento se inició el intercambio epistolar.

Todas las sangres había sido publicada en 1964, y en 1965 fue objeto de duros cuestionamientos por parte de reputados críticos literarios y científicos sociales como Henri Favre, Aníbal Quijano y Jorge Bravo Bresani, en una mesa redonda desarrollada en el local del Instituto de Estudios Peruanos, al que Arguedas era cercano (Rochabrún, ed. 2011). Estos intelectuales -motejados de "doctores" en un importante poema escrito en quechua por Arguedas, Huk doktorkunaman qayay- determinaron que el ambicioso proyecto de la novela no reflejaba adecuadamente la realidad política del campo y de la sociedad peruana de entonces. Se sabe que Arguedas se resintió mucho por estas críticas, al punto de que algunos biógrafos suponen que la Mesa Redonda agudizó la fuerte depresión que ya aquejaba al escritor y que lo había llevado a buscar ayuda desde 1962 en la psicoanalista Lola Hoffman, residente en Chile y de orientación junguiana (ver, por ejemplo, Pinilla 1993).

Es llamativo que el contacto se inicie con la entrega de este ejemplar, dedicado al parecer en castellano a Blanco después de que el escritor redactara muchas frases en quechua. En su carta de agradecimiento, la primera de la serie, Blanco empieza reconviniéndole cariñosamente al escritor por esta decisión de cambio de idioma:

Casi me has hecho llorar, este día, al saber lo que me contó tu esposa. Me dijo: "esto te envía [Todas las sangres, RA]; escribió mucho en quechua y después, 'puede sentir vergüenza de mí' diciendo, se arrepintió y no puso sino estas escuetas palabras" [suponemos en castellano, LAC-GP] ${ }^{4}$. Cuando me dijo esto, yo me dolí mucho; casi lloré. ¿Cómo es posible, taytay, que entre nosotros podamos avergonzarnos de cuanto nos podemos decir en nuestra lengua tan dulce?

Resaltamos el tópico de "esta lengua tan dulce", aún pendiente de análisis desde el enfoque de las ideologías lingüísticas no solo para el caso de Arguedas y Blanco sino, de manera más general, para el quechua ${ }^{5}$. Nos interesa destacar también la llamativa ternura que exhiben estas cartas. Esta disposición afectiva contrasta con el actual discurso, hiperracional y muy reiterativo, de Blanco, y es de destacar también en Arguedas, incluso tomando en cuenta su copiosa e intensa producción epistolar (Forgues, ed. 1993; Murra y López-Baralt, eds. 1996; Pinilla, ed. 2007; Pinilla, ed. 2011a, 2011b; 
Westphalen, comp. 2011), corpus textual que, hay que añadir, muestra una orientación clara hacia el mundo de lo vivido y lo sentido (Núñez 2016).

En efecto, el intercambio está lleno de metáforas y giros discursivos que sorprenden por su afectividad. Blanco, quien trata a Arguedas de "taytay" ("padre" y "señor" en quechua) desde la primera carta, le asegura: "¿Acaso mi corazón no se enternece al leer cómo has traducido al castellano nuestra lengua?". Avanza aún más: "Yo no puedo decir qué es lo que penetra en mí cuando te leo". Le confiesa que no lo lee tan a menudo, pues "mi corazón podría romperse". En una referencia a la naturaleza, tópico inevitable en la retórica amorosa andina, recuerda las punas y las pequeñas quebradas, para luego asegurarle a su interlocutor: “ $¡ C u a ́ n t a s$ veces he pensado en ti cuando me he sentido con esos recuerdos!". Y concluye con una advertencia: "He de resentirme si no envías eso que escribiste para mí”.

Por su parte, Arguedas empieza a desarrollar en su respuesta una metáfora basada en la contradicción o el oxímoron y que mantendrá reservada solo para usarla, reformulada, para referirse a su pareja, en El zorro de arriba y el zorro de abajo ("A Sybila, paloma y acero"). "Hermano Hugo, querido, corazón de piedra y de paloma", le dice primero, para luego asegurar, en un giro mesiánico, que los indios de La Convención y Lares a los que el dirigente ayudó a levantarse tenían también "el alma de piedra y de paloma", alma que "estaba aguardando en lo más puro de la semilla del corazón de esos hombres". Afirma Arguedas que el dirigente es "tan semejante, tan igual a un comunero, lágrima y acero". Y al final, antes de despedirse, diciéndole "Recibe mi corazón”, el escritor se pregunta: “¿Hasta cuándo y hasta dónde he de escribirte? Ya no podrás olvidarme, aunque la muerte me agarre, oye, hombre peruano, fuerte como nuestras montañas donde la nieve no se derrite, a quien la cárcel fortalece como a piedra y como a paloma". Nuevamente la remisión inevitable a la naturaleza y nuevamente el oxímoron.

"Aunque la muerte me agarre": el tema del deceso inminente está también presente en la respuesta de Arguedas. En un momento le confiesa a su interlocutor: "Yo no estoy bien; mis fuerzas anochecen". La grave depresión que acorralaba a Arguedas estaba terminando de hacer su trabajo. En este oscuro rodeo, que culminaría pocos días después, en la Universidad Nacional Agraria, la carta de Blanco puede haber sido una suerte de bálsamo que le permitió al escritor imaginar por un momento un futuro distinto, aunque empedrado de caminos trágicos e incluso sangrientos, para el pueblo con el que se encontraba comprometido (Núñez 2016). "He ahí que te he escrito, feliz, en medio de la sombra de mis mortales dolencias", concluye la carta. Nunca aclararemos del todo si Arguedas llegó a leer la respuesta.

\section{“O actor o nada": radicalización política y crisis personal}

Arguedas le responde a Blanco entre el 11 y el 25 de noviembre de $1969^{6}$. Por esos días, escribió muchas cartas más: las tres que le entregó al lingüista Alfredo Torero la tarde del 28, la que se encontró "junto a su cuerpo dirigida al rector y a los estudiantes de la Universidad Nacional Agraria, que contenía instrucciones para sus funerales" (Vargas Llosa 1996: 13) y, entre otras más, una a su amigo, el etnohistoriador Pierre Duviols, con quien había mantenido correspondencia desde 1958. Ese 21 de noviembre le confía a Duviols que ha vuelto a sus muy malas condiciones y que no sabe bien qué hacer:

Con la novela atragantada en la garganta [El zorro de arriba y el zorro de abajo, LAC-GP], me siento sin ánimo para casi nada y menos para dictar clases. No puedo asegurar qué ha de ser de mí en los próximos días (Pinilla, ed. 2011a: 75).

Signada por la desesperanza y casi anunciando su muerte, esta carta se sitúa en las antípodas de la respuesta a Blanco, no solo por el lirismo y la emotividad que marcan a esta última, sino también por la esperanza manifestada ahí en "ese día que vendrá [...] aquel en que nuestros pueblos volverán a nacer", utopía que Blanco, el destinatario, haría posible. Si a Duviols y a otros amigos cercanos con quienes mantuvo correspondencia les expresa su profunda desazón ("Estoy pasando por la crisis más severa", le escribe a Westphalen el 14 de agosto de 1969 [Westphalen Ortiz, comp. 2011: 244]), a Blanco le hace saber que, gracias a él, capaz de convertir a los indios vencidos por el miedo y el horror a los gamonales "en el más valeroso de los valientes", de fortalecer su alma, gracias a él, morirá "más tranquilo". Es el único a quien siente su igual: "Hermano, querido hermano como yo, de 
rostro algo blanco, del más intenso corazón indio, lágrima, canto, baile, odio".

La respuesta de Arguedas a Blanco no es, en realidad, una carta amical en la línea de las muchas que escribiera a amigos entrañables como el etnohistoriador John Murra y los poetas Manuel Moreno Jimeno y Emilio Adolfo Westphalen. Mal podría serlo, pues ambos no solo no se conocieron personalmente, sino que tampoco establecieron otros vínculos públicos. Por ejemplo, hasta donde se sabe, Arguedas nunca manifestó públicamente su simpatía o apoyo al dirigente durante los años de la toma de tierras en La Convención. Se trata, más bien, de un documento en donde el escritor declara su adhesión a la causa liderada por Blanco, a quien reconoce como el legítimo dirigente cuya revolución liberaría al pueblo oprimido.

La inusitada emotividad del lenguaje empleado por el escritor también canaliza de manera contundente y definitiva la postura revolucionaria y la radicalización política de Arguedas, así como la crisis personal que se agudizó en los últimos años hasta llevarlo a la muerte. Martín Lienhard ha señalado que en los años cincuenta, Arguedas "parecía haberse adherido a la tesis del desarrollismo, doctrina de origen norteamericano que aboga por la necesidad de dinamizar el desarrollo de las áreas de economía 'tradicional' (o de subsistencia) por medio del sistema capitalista" (Lienhard 2015: 77). Como científico social, Arguedas se preguntaba qué pasaría con la cultura andina, cómo esta podría sobrevivir a la intrusión de los valores capitalistas y occidentales. Y si bien en Los ríos profundos, continúa Lienhard, se muestra "la capacidad de movilización de la 'plebe' urbana (las chicheras) y los colonos de hacienda", nada parece "anunciar un 'cambio radical', una 'revolución"” (2011: 77). Pero ya en 1961, apenas dos años después de la publicación de esta novela, Arguedas empieza a ensayar interpretaciones más radicales. Lienhard cita el fragmento de una carta que Arguedas le escribió a Murra, en la que afirma su fe en los colonos "come piojos": "[M]archan al pueblo, a la ciudad capital, a pesar de la metralla. Van por una misa, pero alguna vez avanzarán de ese modo por algo que sea más grande" (Murra y López-Baralt, eds., 1996, cit. en Lienhard 2015: 78). Siete años más tarde (1968), es aún más radical cuando, en una conferencia pronunciada en Cuba, refiriéndose al mismo episodio de los colonos marchando a la ciudad, se pregunta: "Si los indios toman una ciudad, a pesar de que se les trate de impedir el paso con ametrallas y fusiles, por una causa de orden religioso y mágico, ¿no sería posible que tomaran el mismo valor y aún mucho más si fueran impulsados por una razón de tipo social mucho más violenta?" (Lienhard 2015: 78).

La radicalización política de Arguedas se evidencia también, sin duda, en su respuesta a Hugo Blanco (Núñez 2016). Por ser uno de los últimos documentos arguedianos, esta carta deviene, como señala Vargas Llosa, en "otro de sus testamentos, por la fecha y circunstancias en que fue redactada, y por la imagen que Arguedas quiso legar de sí al escribirla, en la lengua de su infancia, en el momento final: la de un escritor comprometido con la revolución y legitimado como tal por el respeto de un líder extremista encarcelado" (Vargas Llosa 1995: 16).

La relación de Arguedas con la teorización política, las luchas sociales, la militancia y las acciones revolucionarias fue complicada y vivida dramáticamente. Con frecuencia se cita aquel párrafo del discurso que pronunció en el acto de entrega del premio Inca Garcilaso de la Vega en 1966 -publicado en El zorro de arriba y el zorro de abajo bajo el título "No soy un aculturado"- cuando, luego de invocar a Mariátegui y a Lenin, afirmó que gracias a ellos encontró "un orden permanente en las cosas", aunque de inmediato se preguntaba:

\begin{abstract}
¿Hasta dónde entendí el socialismo? No lo sé bien. Pero no mató en mí lo mágico. No pretendí jamás ser un político ni me creí con aptitudes para practicar la disciplina de un partido, pero fue la ideología socialista y el estar cerca de los movimientos socialistas lo que dio dirección y permanencia, un claro destino a la energía que sentí desencadenarse durante la juventud (Arguedas 1996: 258).
\end{abstract}

Tras citar una entrevista hecha por Winston Orrillo en la que Arguedas declara que cuando empezó a escribir "era muy radical, en 1931, 1932" y luego fue cediendo, "hasta llegar a creer en la revolución pacífica", Roland Forgues sostiene que, en realidad, el escritor "no pudo llevar a cabo esta radicalización política estimulada más aún por su segundo matrimonio, y su trato con ciertos sectores de la extrema izquierda peruana", debido a que no logró "deshacerse de su viejo sueño utópico de la revolución no violenta y pacífica" (Forgues 
1996: 314). Y cita la respuesta a Hugo Blanco, en la que Arguedas da a entender que si bien celebra el advenimiento de ese "hermoso día que vendrá y del que hablas", él no lo verá, pues habrá muerto. El escritor también expresa su temor de que "ese amanecer cueste sangre, tanta sangre". En el fondo de su corazón, prosigue Forgues, "continuaba siendo fiel a sus opciones no violentas y humanistas" (1996: 315).

Las cartas de Arguedas y los testimonios de aquellos que lo conocieron revelan los padecimientos de quien habita, citando el título del poemario de Washington Delgado (1970), "un mundo dividido": uno marcado por dicotomías irreconciliables y la necesidad permanente de optar. Las dicotomías atraviesan tanto la vida íntima del escritor como su pensamiento político, y cada elección es vivida dolorosa, agónicamente: costeño o andino, socialista o mágico, pequeñoburgués o comunista, Celia o Sybila, etcétera. La respuesta a Blanco -así como las afirmaciones de "¿Último diario?”- informa, finalmente, de una toma de posición radical y definitiva: declararse partidario de la violencia revolucionaria como único camino para la liberación de los pueblos oprimidos. En la carta que le escribe a su editor Gonzalo Lozada dándole instrucciones acerca de la edición de El zorro de arriba y el zorro de abajo, tras anunciarle su decisión de quitarse la vida, explica:

Como estoy seguro que mis facultades y armas de creador, profesor, estudioso e incitador, se han debilitado hasta quedar casi nulas y solo me quedan las que me relegarían a la condición de espectador pasivo e impotente de la formidable lucha que la humanidad está librando en el Perú y en todas partes, no me sería posible tolerar ese destino. $\mathrm{O}$ actor, como he sido desde que ingresé a la escuela secundaria, hace cuarentitrés años, o nada ("Epílogo", en Arguedas 1996: 250).

Entre líneas puede leerse que aun cuando Arguedas tiene la certeza de que el camino de la violencia será el mejor en términos sociales e históricos, él no estará en condiciones de participar en esa lucha. Aduce cansancio y pérdida de facultades, tal vez para no delatar su vacilación ante la anunciada radicalización, y establece una nueva dicotomía: "O actor o nada".
En las entrevistas que sostuvimos, Hugo Blanco recordó más de una vez el deseo manifestado por Arguedas de visitarlo en El Frontón y, con cierta congoja, refirió que él se negó a recibirlo, como lo explica en la segunda carta: no hubieran podido hablar en la cárcel, donde la visita duraba tan solo dos horas. "Contigo tenemos que hablar calmadamente, como hombres serios; sentándonos tranquilos, el corazón plácido, hallpando nuestra coquita, fumando de un solo cigarrillo, perdiendo la vista en los cerros lejanos. Acá no sería así, padre"7. Casi cincuenta años después, el viejo líder revela que más de una vez ha pensado que si esa visita hubiera ocurrido, tal vez Arguedas no se habría suicidado $^{8}$. El exdirigente parece estar convencido de la radicalización política del escritor sin percibir las contradicciones ni el carácter desgarrado de su postura. El sueño que ambos compartían -el triunfo de la revolución ya iniciada- era la mejor razón para seguir viviendo; entonces, de haberse encontrado, tal vez el dirigente, conociendo bien el corazón indígena de su interlocutor, habría conseguido que este les restara importancia a las causas de su deseo de muerte9 .

En una conferencia que dio en el Cuzco el 10 de diciembre de 1986, el historiador Alberto Flores Galindo señaló que la presencia de Hugo Blanco fue "bastante perturbadora" y ejerció "una presión sicológica fuerte en los últimos años de la vida de Arguedas". Blanco era un hombre que no había optado por el mundo académico o universitario, como él, sino "por integrarse al mundo campesino"; en las propias palabras del dirigente, por "acampesinarse" 10 . El derrotero de Arguedas, prosigue Flores Galindo, difería del de Blanco, pues él había transitado, más bien, del mundo campesino al mundo occidental (cit. en Lienhard 2015: 79). Esa dicotomía también se plantea entre la acción política y la actividad intelectual, como se puede comprobar en la confidencia que Arguedas le hace a Murra sobre Sybila Arredondo: "Me escribió una carta desdeñosa a mi actitud de dedicarme a mi trabajo y no a actividades" (Arguedas 1996: 284). A Aníbal Quijano le escribe, en una carta fechada el 4 de enero de 1967, tratando de explicar su primer intento de suicidio. Quijano recuerda que Arguedas apelaba "a la imagen de haber estado viviendo en el 'vientre del monstruo', en un círculo social e intelectual que le era muy grato, pero que le resultaba incoherente con sus nuevas posturas ('son buenas gentes, hasta buenísimas, pero el sumun de la pequeña 
burguesía')" (Quijano 2015: 32). El lingüista Alfredo Torero, cuya amistad con Arguedas data de 1965 y que, tal como Arredondo, se acercó posteriormente a posturas políticas extremistas, parece compartir con Arguedas esta percepción dicotómica:

José María, por el prestigio literario y el ascendiente social que había alcanzado, se veía sometido a solicitaciones y a ofertas de bienes y ventajas por el sistema de poder capitalista reinante, nacional e internacional, mas las rechazaba firmemente, sin rendirse; por otra parte, no se estimaba en capacidad de encabezar un movimiento liberador, para el cual también se sentía solicitado -por las juventudes universitarias, en primer lugar, y por sectores populares potencialmente-. Aunque se estimaba inepto para el liderazgo, señalaba, sin embargo, la vía revolucionaria: la invencibilidad del pueblo, si se rebela y pasa al combate como el de Vietnam; para reforzar este paradigma, se ofrendaba a sí mismo "de pie, no de rodillas" (Torero 2005: 16).

Torero refiere, asimismo, que hacia el 25 de noviembre, reunidos en casa de Racila Ramírez, "cantante puquiana en cuya familia José María era muy querido y recibido a menudo", el escritor le dio al grupo a leer la carta que acababa de dirigir en quechua y en castellano a Hugo Blanco. Ramírez, prosigue Torero, le preguntó por las motivaciones que lo habían llevado a escribirle al líder trotskista:

Respondió que Blanco era quien mejor había interpretado las aspiraciones del campesinado indio y sabido hablarle en su lengua y en sus modos, y mover a la esperanza incluso a los más pobres y despreciados entre los pobres. En especial, le había conmovido, dijo, esa capacidad de devolver la esperanza a quienes, como los siervos de los latifundios serranos, parecían haberla perdido para siempre (Torero 2005: 17).

Desde esta perspectiva, la declaración de Arguedas: "He ahí que te he escrito feliz, en medio de la gran sombra de mis mortales dolencias", en el último párrafo de su respuesta a Blanco, puede leerse, a la luz del mundo dividido que hemos revisado en esta sección, como una manifestación de la imposible conciliación entre la vida (luchar por el advenimiento de "ese día feliz") y las angustias $\mathrm{y}$ tormentos personales del escritor.

\section{Entre "indios verdaderos" con "una lengua tan dulce"}

Volvamos ahora por un momento al episodio inicial de este intercambio epistolar, la entrega del ejemplar de Todas las sangres por vía de Sybila Arredondo. No es casual la elección de este libro: por un lado, se trataba de la última novela que el escritor había publicado, lo que vuelve muy natural el regalo, pero, por otro, no hay que olvidar lo importante que había sido para Arguedas el debate desatado por la Mesa Redonda de 1965 en el Instituto de Estudios Peruanos (Rochabrún, ed., 2011; Pinilla 1993). En la carta a Blanco, Arguedas recuerda esta discusión y muestra esas heridas:

Los críticos de literatura, los muy ilustrados, no pudieron descubrir al principio la intención final de la novela, la que puse en su meollo, en el medio mismo de su corriente. Felizmente uno, uno solo, lo descubrió, y lo proclamó, muy claramente.

Probablemente este crítico agudo era el lingüista y literato Alberto Escobar, el único que tuvo una posición favorable a la novela en la Mesa Redonda (Rochabrún, ed., 2011, ver especialmente la introducción). En su respuesta, Blanco capta la demanda y aborda en un lugar muy destacado esas críticas:

Desde mucho antes sabía que éramos un solo corazón, no solamente leyendo Los ríos profundos; sino que, leyendo cualquier cosa que escribes, mirando cualquier cosa que haces, se trasluce tu ser indio. ¿Iba a esperar yo a escuchar lo que dijeran los críticos? Que hablen lo que quieran esos mistis, mi corazón está mirando al tuyo en lo que escribes, allí apareces como en agua clara.

La referencia a los críticos como esos mistis, como el otro, el no indio, permite iniciar la construcción de la indigenidad de ambos interlocutores de manera esencialista y polarizada. Recuérdese que en el continuum étnico-racial cuzqueño de la 
época (indio / mestizo / misti o "blanco") se trata justamente de los extremos. Blanco continúa:

No sé qué verán los mistis en ellos [tus escritos, LAC-GP]; y para que les digan "Ese es buen crítico", hablan una u otra cosa. Es imposible que ellos vean tu corazón, aunque se los estés mostrando. El misti es misti, padre. En cuanto a ser buenas personas, algunas son realmente buenas personas, no les estoy insultando. Pero tu corazón, solo tus congéneres indios lo vemos bien. Los mistis, aun siendo buenas personas, para eso son ciegos que miran. Ellos no sollozan temblorosos como nosotros al leer tus escritos. Imposible, padre, el misti es misti.

En las entrevistas que sostuvimos con el dirigente campesino, nos sorprendió encontrar que él seguía manteniendo esta visión esencialista y excluyente de la indigenidad. Aquí es pertinente recordar que ambos, Arguedas y Blanco, proceden de familias mistis o "blancas" de Apurímac y Cuzco, respectivamente. Arguedas, hijo de un abogado y, por el lado de su madre, tempranamente muerta, de una familia de comerciantes de Andahuaylas; Blanco, también hijo de abogado y, por el lado materno, de una familia de antiguos hacendados de Paruro, los Galdós ${ }^{11}$. Cuando le preguntamos a Blanco por las posibles contradicciones entre su autodefinición como indígena y sus orígenes familiares "blancos", nos respondió remitiéndonos a un breve ensayo del escritor uruguayo Eduardo Galeano, quien argumenta que Blanco "nació dos veces", una como misti y la otra como campesino indígena, cuando, en la pubertad, fue testigo del abuso cometido por un gamonal contra un peón, al que había marcado con hierro candente en las nalgas con las iniciales de su nombre. Galeano concluye:

No era tan anormal el hecho, pero esa marca marcó a Hugo para siempre. Y con el paso de los años, se fue haciendo indio este hombre que no era, y organizó los sindicatos campesinos y pagó con palos y torturas y cárcel y acoso y exilio su desgracia elegida (cit. en Blanco Galdos 2017: 256).

En este punto, conviene volver al otro inicio de esta historia epistolar: las dudas que sintió
Arguedas al escribirle una dedicatoria en quechua al dirigente campesino. Siendo ambos mistis de origen y bilingües desde la infancia, parecen concentrar en el quechua la marca de su indigenidad, a pesar de que también existe un quechua que se puede calificar de "mestizo", especialmente en la región surandina y particularmente en el Cuzco (Mannheim 2013). Nada mejor, sin embargo, que el manejo del idioma ancestral, esa "lengua tan dulce", para empezar a construir la indigenidad de manera recíproca entre ambos actores. ¿Por qué la duda entonces? Lo que Blanco reporta en el discurso citado de Arredondo es que Arguedas había dicho: "Puede sentir vergüenza de mín". Preguntado sobre las razones de esta vergüenza, el dirigente duda: "No sé, porque creería que soy civilizado, no sé уо..." (entrevista, 30/09/2016) ${ }^{12}$. Se podría especular mucho respecto de esta vergüenza idiomática inicial en torno a una lengua que finalmente resultó clave para la interacción, pero queremos enfatizar dos aspectos que a nuestro modo de ver son más significativos en este diálogo.

En primer lugar, desde la perspectiva de ambos interlocutores y en su condición de hablantes bilingües, hay una diferencia radical entre el español y el quechua. Hugo Blanco le atribuye de manera explícita al idioma indígena el lugar de los afectos, haciendo una oposición con la frialdad y la dureza del castellano, asociado con frecuencia a la palabra escueto. Así, el quechua es capaz de expresar el mundo y la riqueza de los sentimientos, a diferencia del español:

Cuando nos pedimos ayuda, nunca lo hacemos con palabras escuetas, en nuestra lengua. ¿Acaso alguna vez escuchamos decir: "Mañana has de ayudarme a sembrar porque yo te ayudé ayer”? ¡Ahj! Qué asco $[\ldots]$ ¿Acaso entre nosotros, entre nuestra gente, nos hablamos de ese modo? Muy tiernamente nos decimos: "Señor mío, vengo a pedirte que me valgas; no seas de otro modo: mañana hemos de sembrar en la quebrada de abajo; ¡ayúdame pues, caballerito, paloma mía, corazón!". Con estas palabras solemos empezar a pedir que nos ayuden.

La mención del corazón como sinécdoque del mundo afectivo es persistente en estas cartas. Blanco le hace saber a Arguedas que cuando lo 
ha leído, ha temido un quiebre total: "mi corazón podría romperse". También le confiesa que no puede hablar plenamente en castellano: "solo cuando hablo en quechua digo exactamente lo que brota de mi corazón y de mi boca". En las entrevistas recientes, el dirigente sigue convencido de ello: "El castellano no me alcanza porque es pobre afectivamente" (entrevista, 18/01/2017). Como se ve en el fragmento antes citado, palabras que en español no se dirían entre hombres (caballerito, paloma mía, corazón) caracterizan, desde el punto de vista de Blanco, las prácticas comunicativas en la lengua indígena. Así, se le asigna al quechua una capacidad para expresar los sentimientos, el amor y la amistad de la que el castellano carece totalmente.

En segundo lugar, el quechua resulta clave en el intercambio porque el nosotros indígena entre Blanco y Arguedas emerge en y sobre el quechua desde la primera carta, en el sentido de que no solo es la lengua elegida para esta comunicación (en quechua) sino que, además, como hemos visto, la reflexión metalingüística (sobre el quechua) introduce rasgos esenciales del "ser indígena". Ello conduce a Blanco a la reconvención que citamos al inicio: "Y siendo así, ¿crees que pude haberme dolido de cualquier cosa que hubieras escrito en nuestra lengua, para mí?" (énfasis nuestro). Arguedas responde de manera efusiva, e integra en su discurso también la lengua originaria y la identidad étnica, recordando a los indios que lo acogieron en Puquio, cuando era un niño y fue desterrado a la cocina por su madrastra (Merino de Zela 1991 [1970]; Pinilla 2004):

Tu sangre ya está en la mía, como la sangre de don Victo Pusa, de don Felipe Maywa. Don Victo y don Felipe me hablan día y noche, sin cesar lloran dentro de mi alma, me reconvienen en su lengua, con su sabiduría grande.

Y luego el escritor confirma la separación esencial entre los indios, como aquellos que lo criaron $\mathrm{y}$ ahora le hablan internamente en quechua, y los mistis, cuando concluye:

He aquí que te he escrito, feliz, en medio de la gran sombra de mis mortales dolencias. A nosotros no nos alcanza la tristeza de los mistis, de los egoístas; nos llega la tristeza fuerte del pueblo, del mundo, de quienes conocen y sienten el amanecer.
La autenticidad indígena termina siendo construida, pues, relacionalmente, como destaca Bucholz (2003); mediante el reconocimiento mutuo de la reconversión que han experimentado estos mistis de nacimiento, "de rostro algo blanco", como reconoce Arguedas, para volverse después "del más intenso corazón indio". No es casual la coincidencia de sus exaltadas reacciones ante esta confirmación. Blanco le confiesa al escritor, en su segunda carta, lo que despertó en él la lectura de Los ríos profundos: "A ti, ya estando en la cárcel de Arequipa, te conocí bien. Y al conocerte dije: ' $Y Y a$ está, carajo, ahora el mismo indio está hablando!'”. Y Arguedas le confía que al leer su primera carta había pasado inquieto la noche entera, "con la fuerza de la alegría y de la revelación". El activista político colombiano Carlos Vidales, quien pasaba unos días en Lima por esas fechas cerca de la pareja Arguedas-Arredondo, refirió que Arguedas exclamó, al leer la carta: “ ¡Es un indio! ¡Puro indio!” (Vidales 1975). La revelación mutua era, pues, la de la propia indigenidad.

\section{Conclusión}

La importancia del quechua y la revelación recíproca, en espejo, de la indigenidad anhelada marcan este intercambio epistolar entre dos figuras centrales de la historia política y cultural peruana de fines de la década de 1960. Mistis devenidos en indios por diferentes razones biográficas, Arguedas y Blanco se construyen recíprocamente como portavoces de los sectores indígenas secularmente oprimidos por un sistema basado en la explotación y el despojo. No nos toca evaluar, ni mucho menos, la importancia que efectivamente ambos tuvieron, en sus respectivos campos de acción, para empezar una lenta transformación de ideas, sensibilidades y estructuras sociales en el Perú, a favor de las causas de los pueblos originarios. Sí queremos resaltar, en cambio, el carácter central que tiene para ellos la tarea permanente, parcial, inacabada y contradictoria, de la construcción identitaria (Bucholz y Hall 2005). El sentido subjetivo de este intercambio epistolar, lo vemos ahora más claro, puede formularse como la confirmación de la autenticidad indígena por medio del reconocimiento recíproco, un reconocimiento canalizado por la referencia constante y el recurso instrumental a esa "lengua tan dulce" que les permite a ambos actores desplegar una ternura y 
emotividad que imaginan imposibles de canalizar en castellano.

La muerte, ese personaje inevitable, también está presente en estas cartas, pero de distintas maneras. Mientras que Arguedas se siente ya "agarrado" por ella" ${ }^{13}$ "en medio de la sombra" de "mortales dolencias", Blanco está seguro de que habrá "otro día", no solo en un sentido político y mesiánico -que también está presente en los textos-, sino de una manera más concreta: habrá "otro día" puntual, para que Arguedas y él puedan encontrarse, como ya hemos citado, "sentándonos tranquilos, el corazón plácido, hallpando nuestra coquita, fumando de un solo cigarrillo, perdiendo la vista en los cerros lejanos". Asegura confiado el dirigente:

[T]e haré llamar un día, padre; cuando haya algo de calma; por lo menos para contemplar tu venerado rostro, por lo menos para apretar tu corazón al mío.

Mientras llegue ese día, así te escribiré cada vez, volcando mi corazón al tuyo.

Como ya sabemos, no es del todo claro si Arguedas leyó estos amorosos anuncios, pues solo unos días después la muerte terminó por cercarlo.

\section{Referencias Citadas}

Andrade Ciudad, L. y J. I. Pérez Silva.

2011 Perusuyunchikpa qichwasiminkuna. Los quechuas del Perú. Lima, Unicef / Pontificia Universidad Católica del Perú [videograbación].

Arguedas, J. M.

1996 El zorro de arriba y el zorro de abajo. Edición crítica. E.-M. Fell, coord. Madrid, París, México, Buenos Aires, São Paulo, Río de Janeiro, Lima: Allca XX / Ediciones Unesco. Colección Archivos 14.

Blanco Galdós, $\mathrm{H}$.

2017 Nosotros los indios. Tercera edición corregida y aumentada. Cuzco: Centro de Estudios Regionales Andinos Bartolomé de Las Casas / Programa Democracia y Transformación Global.

Blanco, $\mathrm{H}$.

1969 "Correspondencia entre Hugo Blanco y José María Arguedas" (1969). Amaru 11-12, diciembre, pp. 13-14.

Bucholtz, M.

2003 "Sociolinguistic nostalgia and the authentication of identity". Journal of Sociolinguistics 7, 3, pp. 398-416.

Bucholtz, M. y K. Hall

2005 "Identity and interaction: a sociocultural linguistic approach". Discourse Studies 7, 4-5, pp. 585-614. DOI: $10.1177 / 1461445605054407$.

Cerrón-Palomino, R.

1997 "El legado amoroso del quechua". Perú El Dorado 8, pp. 45-46.

Craig, W. W.

1968 El movimiento campesino en La Convención, Perú. La dinámica de una organización campesina. Serie Documentos Teóricos 11. Lima: Instituto de Estudios Peruanos.

Delgado, W.

1970 Un mundo dividido. Poesía, 1951-1970. Lima: Casa de la Cultura del Perú.

Fioravanti, E.

1974 Latifundio y sindicalismo agrario en el Perú. El caso de los valles de La Convención y Lares (1958-1964). Lima: Instituto de Estudios Peruanos.

Forgues, R.

1996 “¿Por qué bailan los zorros?”. En Arguedas 1996: 307-315.
Forgues, R., ed.

1993 José María Arguedas. La letra inmortal. Correspondencia con Manuel Moreno Jimeno. Lima: Ediciones de Los Ríos Profundos.

Handelman, $\mathrm{H}$.

1975 Struggle in the Andes. Peasant political mobilization in Peru. Austin: University of Texas Press.

Harding, C.

1975 "Land reform and social conflict in Peru". En A. F. Lowenthal, ed. The Peruvian experiment. Continuity and change under military rule. Princeton / Londres: Princeton University Press, pp. 220-253.

Lienhard, M.

2015 “¿Ficción o realidad. El poder de Todas las sangres”. En Pinilla 2015: 73-99.

Mannheim, B.

2013 El futuro de los idiomas oprimidos en los Andes, de Xavier Albó, cuarenta años después. Crónicas Urbanas, 16-17, pp. 113-118.

Merino de Zela, M.

1991 [1970] "José María Arguedas: vida y obra". En R. Montoya, comp. José María Arguedas, veinte años después: huellas y horizonte, 1969-1989. Lima: Universidad Nacional Mayor de San Marcos, pp. 99-115.

Murra, J. y C. López-Baralt, eds.

1996 Las cartas de Arguedas. Lima: Fondo Editorial de la Pontificia Universidad Católica del Perú.

Núñez, G.

2016 "Autorretrato de un escritor del Perú del siglo XX: revelaciones en las cartas de José María Arguedas". Ponencia presentada en el Congreso de la Latin American Studies Association (LASA) 2016, Nueva York.

Pinilla, C. M.

1993 Arguedas: conocimiento y vida. Lima: Pontificia Universidad Católica del Perú.

Pinilla, C. M.

2004 "Cronología”. En J. M. Arguedas. ¡Kachkaniraqmi! iSigo siendo! Textos esenciales. Lima: Congreso de la República del Perú, pp. 37-44. 
Pinilla, C. M., ed.

2007 Apuntes inéditos. Celia y Alicia en la vida de José María Arguedas. Lima: Fondo Editorial de la Pontificia Universidad Católica del Perú.

Pinilla, C. M., ed.

2011a "Cartas de Arguedas a Abelardo Oquendo en el Archivo Arguedas de la PUCP". Anthropologica 29, pp. 155-166.

Pinilla, C. M., ed.

2011b Itinerarios epistolares. La amistad de José María Arguedas y Pierre Duviols en dieciséis cartas. Lima: Fondo Editorial de la Pontificia Universidad Católica del Perú.

Pinilla, C. M., ed.

2015 Todas las sangres, cincuenta años después. Lima: Ministerio de Cultura.

Pucci, V. y F. Wainziger Friedheim

2013 “'Rostro algo blanco, corazón indio'. Narrativas de la resistencia decolonial en la correspondencia entre José María Arguedas y Hugo Blanco. Reflexiones desde la (de)colonialidad y el género". Ponencia presentada a la Mesa Temática "Las fuentes de la historia desde el género poscolonial / decolonial". XIV Jornadas Interescuelas / Departamentos de Historia, 2-5 de octubre. Universidad Nacional de Cuyo.

Quijano, A.

2015 "La vasta empresa narrativa de Todas las sangres". Entrevista realizada por Carmen María Pinilla el 4 de septiembre de 2014. En Pinilla, ed. 2015: 27-47.
Rochabrún, G., ed.

2011 ¿He vivido en vano? La Mesa Redonda sobre Todas las Sangres del 23 de junio de 1965. Lima: Instituto de Estudios Peruanos.

Tauro del Pino, A.

2001 Enciclopedia ilustrada del Perú. Tomo 3. Lima: Peisa.

Thorp, R.

1995 Gestión económica y desarrollo en Perú y Colombia. Lima: Universidad del Pacífico.

Thorp, R. y G. Bertram

[1985] 2013 Perú: 1890-1977. Crecimiento y políticas en una economía abierta. Lima: Universidad del Pacífico.

Torero, A.

2005 Recogiendo los pasos de José María Arguedas. S. 1.: Libros en Red. Colección Insumisos Latinoamericanos.

Vargas Llosa, M.

1996 La utopía arcaica. José María Arguedas y las ficciones del indigenismo. México D. F.: Fondo de Cultura Económica.

Vidales, C.

1975 "Arguedas: su corazón, rey entre sombras". Estravagario. Revista cultural de El Pueblo de Cali. 19 de octubre. Reproducido en: <http://hem.bredband.net/rivvid/carlos/ ARGUED.HTM $>$.

Westphalen, I., comp.

2011 El río y el mar. Correspondencia, José María Arguedas / Emilio Adolfo Westphalen (1939-1969). Lima: Fondo de Cultura Económica.

\section{Notas}

1 Este trabajo fue financiado por la Dirección de Gestión de la Investigación de la PUCP, mediante la subvención DGI2015-291, proyecto "Historias de vida de líderes indígenas: una mirada interdisciplinaria". Agradecemos a los dos evaluadores anónimos que comentaron el texto. Asimismo, a María Blume, Susana Frisancho, Roger Gonzalo Segura, Jorge Iván Pérez Silva y Miguel Rodríguez Mondoñedo por sus valiosas observaciones para mejorar el argumento. Finalmente, a Rosario Basay Vega, Nicanor Domínguez Faura y Patricia Ledesma Liébana por sus recomendaciones bibliográficas para entender mejor el período. Todas las fallas que subsistan son de nuestra responsabilidad.

2 Se trató de cuatro entrevistas, de entre 30 y 75 minutos, realizadas por los autores el 30/09/2016, el 18/01/2017, el 17/02/2017 y el 10/01/2018. Antes de estas, a lo largo del 2016, el proyecto desarrolló entrevistas más generales acerca de la biografía del dirigente. En ellas participó Andrade junto con Andrés Napurí, Enrique Delgado y Susana Frisancho, a quienes agradecemos.

3 Para un examen general del movimiento campesino peruano en el período, se puede consultar Handelman 1975. Este autor presenta un útil e informado resumen del contexto sociohistórico en que se produjo el movimiento de La Convención y Lares (pp. 70-76). El trabajo clásico pertinente a este último es Craig 1968, pero tiene un sesgo negativo hacia el papel de Blanco.

4 Las siglas RA se refieren a la revista Amaru, dirigida por el poeta Emilio Adolfo Westphalen, que publicó las cartas por primera vez. Las siglas LAC-GP se refieren a los autores de este artículo. Citamos a partir de la traducción al castellano de esta carta. El original de la primera carta, en quechua, también fue publicado por Amaru. En cuanto a los originales en quechua de las otras dos cartas, no se sabe dónde están y no han sido publicados. La segunda carta de Blanco y tercera del intercambio, que, al parecer, Arguedas no llegó a leer antes de suicidarse, fue traducida del quechua al castellano por el propio dirigente campesino a pedido de Arredondo. Los avatares de la traducción de este material serán materia de un estudio posterior.

5 Sin embargo, ya en Cerrón-Palomino (1997) se puede ver un interesante planteamiento del tema. El documental Perusuyunchikpa qichwasiminkuna. Los quechuas del Perú (Andrade y Pérez Silva 2011) recoge este discurso de manera profusa, pues durante el trabajo de filmación, la asociación entre el quechua y el atributo "dulce" (miski en el idioma indígena) surgió constantemente en las distintas regiones quechuahablantes visitadas.

6 La carta no está fechada. Las fechas límite señaladas son las de la primera y la tercera cartas del intercambio. Vargas Llosa señala categóricamente que la respuesta a Blanco fue escrita "sin duda cuatro días antes de su muerte" (1996: 15). Aquí hay un error: tal vez haya querido decir cuatro días antes de que se disparara el balazo en la sien (el viernes 28 de noviembre). Recuérdese que Arguedas murió, tras permanecer en coma, el 2 de diciembre, cuatro días después de dispararse.

7 Hallpay: masticar coca en quechua cuzqueño y de ahí hallpar en castellano andino sureño. 
8 Recuérdese, sin embargo, que no se tiene la certeza de que Arguedas haya leído esta segunda carta. Según Blanco, Arredondo le informó que Arguedas dijo al recibirla: "La voy a leer el lunes" (lunes primero de diciembre), pero se disparó el viernes 28 de noviembre (entrevista, 30/09/2016); es decir, habría muerto sin leerla.

9 El dirigente piensa que la causa de la depresión y de la decisión de suicidarse por parte de Arguedas estaba en percibir la inminente decadencia de la cultura indígena y del quechua, como consecuencia de la modernización y de las grandes migraciones: "En El zorro de arriba y el zorro de abajo, él vio la decadencia del pueblo quechua; cómo va civilizándose, cómo va olvidándose lo que es quechua y todo eso en Chimbote, ¿no?, cuando va. Entonces, parece que él creía que nuestra cultura iba a morir" (30/09/2016). Y en otra entrevista: "Creo que lo mató lo que veía la decadencia de la cultura indígena. Por eso $E l$ zorro de arriba y el zorro de abajo trata de eso, pero no la termina. Cuando el indio va a Chimbote a trabajar y ahí ya no habla quechua, se disfraza de misti, etcétera, ¿no?, y probablemente prohíbe a sus hijos que hablen quechua, ya no les habla en quechua..." (18/01/2017). Añade una idea particular al respecto: "Si Arguedas viviera ahora, no se suicidaría. ¿Por qué? Porque hay una reemergencia de lo indígena a nivel mundial. ¿Por qué? Por el ataque que hay a la naturaleza" (17/02/2017). Y en otra entrevista: "Por eso yo digo: si José María estuviera vivo ahora, no se suicidaría, porque hay un renacimiento de todo lo indígena, entre ellos el quechua [...], y hay menos gente ahora que se avergüenza de ser Huamán o de ser Quispe ¿no? Y hay, pues, un renacimiento: la gente tiene seudónimos quechuas y todo eso. Entonces, ahora está renaciendo el orgullo de ser indígena, en todo el mundo. Y entre ellos el quechua. Y esto ¿por qué es? Por lo que llaman 'el buen vivir' los indigenistas" (30/09/2016).

10 Vale la pena insistir acá en los orígenes mistis o "decentes" (de ascendencia "blanca" y occidental) de la familia (sobre todo materna) de Blanco. Después de terminados sus estudios escolares, sus padres lo enviaron a estudiar a Argentina (a la Universidad de La Plata), como hacían en ese tiempo los jóvenes cusqueños de la clase alta. Ningún "indio" ni "mestizo", en el sentido cusqueño del término, hubiera soñado siquiera con ello. En Buenos Aires recibió su formación marxista y trotskista, y el
Partido Obrero Revolucionario (sección argentina de la IV Internacional) le recomendó insertarse, a su vuelta al Perú, en los sindicatos obreros de las principales ciudades. Por eso, de Buenos Aires Blanco viajó directamente hacia Lima, no hacia el Cusco. En Lima, la Policía le siguió los pasos por haber participado en las protestas contra la visita del entonces vicepresidente de Estados Unidos, Richard Nixon (Blanco Galdós 2017: 62); por eso, le fue imposible insertarse en los sindicatos limeños y regresó a su ciudad de origen. Ahí, en la Federación Obrera, se dio cuenta de que esta era una organización de artesanos, no de obreros, de que el Cuzco no era una ciudad industrial, y de que "la vanguardia" estaba en los sindicatos campesinos de La Convención. Fue entonces que miró hacia el campesinado y se comprometió con este. Este tramo de la trayectoria política de Blanco es clave para entender cabalmente la historia de su indigenidad y para sopesar bien su relación con el quechua. Él hablaba esta lengua desde niño, pues su madre, Victoria Galdós Mendoza vda. de Blanco, en tanto hacendada, tenía que manejarla para comunicarse con los indios. Blanco también refirió que su madre y su padre, Miguel Ángel Blanco Villafuerte, un abogado de origen mestizo (no misti ni de familia hacendada sino hijo de panaderos), solían comunicarse en quechua y no solo en castellano; también le hablaban a él en quechua (entrevista, 17/02/2017). Handelman (1975: 74) ha resaltado el peso que tuvo el manejo fluido de la lengua indígena en el liderazgo de Blanco.

11 Fioravanti yerra cuando afirma que Blanco es de madre campesina (Fioravanti 1974: 192). Es crucial anotar que, en este punto, como en todos los datos biográficos que maneja de Hugo Blanco, Fioravanti se guió de la percepción -a veces errada- de los propios campesinos cuzqueños. Tauro del Pino (2001) tampoco acierta cuando afirma que Blanco nació "en una familia de clase media".

12 Civilizado es un calificativo claramente negativo en el discurso de Blanco: equivale a haber perdido los valores solidarios y colectivistas de las culturas indígenas, entendidos como los valores ancestrales (no civilizados) de la humanidad.

13 Hay aquí un interesante calco semántico del quechua en el castellano de la traducción, también presente en el castellano andino sureño. En la lengua indígena, las enfermedades "agarran" al sujeto. El verbo correspondiente es hapiy. 
